\title{
Pelvic floor muscle training with and without biofeedback in treatment of overactive bladder
}

\author{
Preethi Badda, Achla Batra, Sheeba Marwah*, Rupali Dewan
}

Department of Obstetrics and Gynecology, VMMC and Safdarjung Hospital, New Delhi, India

Received: 24 December 2018

Revised: 14 June 2019

Accepted: 01 July 2019

*Correspondence:

Dr. Sheeba Marwah,

E-mail: sheebamarwah901@gmail.com

Copyright: (c) the author(s), publisher and licensee Medip Academy. This is an open-access article distributed under the terms of the Creative Commons Attribution Non-Commercial License, which permits unrestricted non-commercial use, distribution, and reproduction in any medium, provided the original work is properly cited.

\begin{abstract}
Background: Overactive bladder $(\mathrm{OAB})$ is a commonly encountered problem in gynaecological practice. It has profound effect on quality of life (QOL), affecting simple daily activities as well. Prevalence rates of OAB in Asians are $53.1 \%$. The first line management of $\mathrm{OAB}$ is behaviour modification and pelvic floor muscle training (PFMT). Objective of this study was to comparative assessment of biofeedback assisted PFMT (BAPFMT) versus PFMT alone in treatment of OAB using strength of pelvic floor muscle and QOL before and after treatment.

Methods: A prospective comparative randomized controlled trial was conducted to compare the effect of PFMT versus BAPFMT on OAB symptoms over period of 12 weeks. Total of 100 patients fulfilling inclusion and exclusion criteria were selected. Randomization of patients was done into two groups of 50 patients each; half of them were subjected to PFMT and other half to BAPFMT. Appropriate statistical test were applied.

Results: At the end of 12 weeks of intervention, there was a significant improvement in pelvic floor muscle strength and QOL in both groups $(\mathrm{p}<0.001)$. The improvement in pelvic floor muscle strength was more with BAPFMT; however there was no difference in improvement of QOL between the groups.

Conclusions: Addition of biofeedback to PFMT may be a useful adjunct in OAB patients.
\end{abstract}

Keywords: King's health questionnaire, Modified oxford scale, Overactive bladder symptom score

\section{INTRODUCTION}

Overactive bladder syndrome is defined by the International Continence Society (ICS) as urgency with or without urge urinary incontinence (UUI), usually with frequency and nocturia. ${ }^{1}$ Prevalence of overactive active bladder (OAB) in Asians goes up to $53.1 \% .^{2}$ Its incidence increases with age.

$\mathrm{OAB}$ has a profound effect on quality of life (QOL), impacting even simple daily activities, like work, travel, interpersonal activities, physical activity, sexual function, and sleep, thus necessitating effectual management. ${ }^{2}$
Women with nocturia report lack of energy, chronic fatigue, and difficulty in performing daily activities. Nocturia has been correlated with reduced QOL, disturbed sleep, and poor health. ${ }^{3-5} \mathrm{OAB}$ with incontinence diminishes overall QOL, creating additional health problems for the sufferer. These lead to an enhanced risk of falls and fractures, urinary tract and skin infections, sleep disturbances, and depression. ${ }^{6-9}$

OAB though being multifactorial in etiology, is typically attributed to be caused by early, uncontrolled contraction (spasms) of the bladder muscle (detrusor muscle), resulting in an urge to urinate. It is thus primarily a 
problem of the nerves and bladder muscles that allow for early contraction during the normal relaxation phase of bladder filling, leading to manifestation of symptoms. ${ }^{10}$

Both non-pharmacologic and pharmacologic treatments are known to exist for OAB. Behavioural therapy, also called behavioural modification, is a treatment approach that aims to alter an individual's actions or environment to improve bladder control.

\section{Components of behavioural therapy include}

- Education

- Dietary and lifestyle modification

- Bladder training

- Pelvic floor muscle therapy (PFMT)

- Self-monitoring with bladder or voiding diaries. ${ }^{11}$

PFMT is one of the important modalities for treating $\mathrm{OAB}$. The rationale of pelvic floor muscle exercise is to improve the timing of contractions, the strength of the pelvic floor muscles and the tone of the pelvic floor muscles. Thus, voluntary pelvic floor muscle contractions in a patient are used to control the symptoms of urgency and urge incontinence. After inhibiting the urgency to void and the detrusor contraction, the patient can reach the toilet in time to avoid urine leakage.

PFMT has shown a good success rate in cases of stress urinary incontinence and is also showing promising results for $\mathrm{OAB}$ in recent times. ${ }^{12,13}$ But, it is often difficult for a woman to identify correct pelvic floor muscle group during PFMT; hence addition of biofeedback helps her to recognize the correct group of pelvic floor muscles. ${ }^{14-16}$ However there is a dearth of randomized control trials comparing the efficacy of BAFMT with PFMT alone.

Keeping this in mind, the present study was proposed to compare the strength of pelvic floor muscles before and after treatment with BAPFMT and PFMT, and to compare the effect on quality of life after these two forms of treatment.

\section{METHODS}

To study the difference between improvement in symptoms and quality of life of patient receiving Biofeedback assisted pelvic floor muscle training (BAPFMT) versus PFMT, a randomized controlled trial was conducted in department of Obstetrics and Gynaecology of VMMC and Safdarjung hospital in collaboration with department of urology and physical and medical rehabilitation from October 2014 to January 2016. In this study, women with $\mathrm{OAB}$ attending the gynecology/urology OPD were enrolled. Ethical permission from the institutional ethical committee was taken before conducting the study. A sample of 50 patients per group including $10 \%$ lost to follow up are required, assuming alpha - level of significance at $5 \%$, power- $80 \%$ and effect size- 0.6 (Reference-G power 3.1 is used for calculation).

After taking their written informed consent, women were subjected to the eligibility criteria, and a total of 100 women fulfilling the inclusion criteria were selected. The inclusion criteria were: Women aged> 18 years, having symptoms of $\mathrm{OAB}$, and were willing to follow up diligently. Antenatal women, women who had delivered within three months, those having active urinary tract infection, interstitial cystitis/tubercular, cystitis/history of tuberculosis, neurologic diseases(stroke/multiple sclerosis/spinal cord injury), women with medically complicated/uncontrolled diabetes mellitus; those with faecal motility disorder (fecal incontinence/constipation), chronic pelvic pain; presence of gross haematuria, previous pelvic/vaginal surgeries ,Pelvic cancers (bladder/colon/cervix/uterus cancer)/ pelvic radiation, were excluded from the study.

A detailed history was taken from each participating woman followed by a comprehensive abdominal, gynaecological and neurological examination of all the included women, and relevant investigations (Urineroutine and microscopy, urine culture if required, Blood sugar (fasting and post prandial), USG for post void residual urine) were done. Behavior therapy was given to all women, and they were asked to maintain bladder diary for three days. The pelvic floor muscle strength of all subjects was then assessed by the investigator using Oxford scale and maximal vaginal squeeze pressure measured by Piriton perineometer. ${ }^{17}$ Modified oxford scale-for digital evaluation of pelvic floor contraction strength; Score is from 0-5. (0-nil, 1-flicker of muscle contraction, 2-weak contraction, 3-medium: slight lift of examiner's finger with no resistance, 4-strong: elevation of examiner's finger against light resistance, 5-very strong: elevation of examiner's finger against strong resistance.

Also QOL was measured by King's health questionnaire. $^{18}$ QOL I consists of two parametersgeneral health perception (GHP) and incontinence impact. Score is calculated from the formulae given in King's health questionnaire. Score of GHP is 1-5 and incontinence impact is 1-4 [Formulae: (score to GHP-1/4) $\mathrm{x} 100$, (score of incontinence impact-1/3) x100].

QOL II consists of seven parameters-role limitation, social limitation, physical limitation, personal relationship, sleep, emotions and severity measures. Score for all parameters is between (0-3). [Formulae:(score to role limitation-2/6)x100,(score to physical limitation-2/6)x100, (formulae of role limitation if score is equal to or more than 1 then: (score to role limitation -3/9) $\times 100$ and if score is zero then: (score to role limitation-2/6)x100, formulae for personal relationship if score is equal to or more than 2: (score to personal relationship-2/6) $\times 100$, if score is equal to 1 : (score to personal relationship-1/3) $\times 100$, if score is zero 
then treat as missing value, (score to emotions-3/9)x100, (score to sleep-2/6)x100, (score to severity measures4/12)x100].

Then all the females were given dietary and behavior modification, by changes in the amount and type of fluid consumed (eg. decreasing consumption of caffeinated and carbonated beverages) and by bladder training in which patient was educated about scheduled voiding regime, urgency control and relaxation techniques.

The women were then randomized into two groups of 50 each, using computer sequenced envelopes. Group A was subjected to PFMT by trained physiotherapist in the department of physical rehabilitation; while women in Group B received BA PFMT using LABORIE machine. (All the patients were sent to physical medical rehabilitation department for baseline pelvic floor muscle training and biofeedback assisted training was done in gynecology department by gynecologist).

\section{Exercise regimen in Group A}

Patients were asked to empty her bladder and lie down in a dorsal lithotomy position and make sure that her buttocks and tummy muscles are relaxed. They were asked to locate pelvic floor muscles by squeezing them as if trying to stop flow of urine/stool. If any patient was not able to locate her pelvic floor muscles, then clinician placed a finger in vagina and asked her to lift the finger of clinician and she was asked to keep it lifted till the count of five. If she was not able to lift for so long then she was asked to begin by squeezing those muscles for 2 3 seconds and to increase the time of lift to 10 seconds. She was advised to relax her pelvic muscles for 10 seconds in between two squeezes. A set of 10 contractions of 10 second duration with 10 seconds rest was done in each session. Patient was instructed to repeat the session of 10 contractions three times a day at home daily till her next visit.

\section{Exercise regimen in Group B}

Biofeedback was provided by Urostym (Laborie) system. The patient was asked to empty her bladder and lie in supine position as in PFMT. A vaginal probe covered by a condom was placed intravaginally to record the pressure of pelvic floor muscles and surface patch electrodes were applied abdominally, one on each side of abdomen for recording abdominal muscle tone. The patient was asked to squeeze the probe while keeping abdominal muscles relaxed. The biofeedback system displayed the electrical signals of the pelvic floor muscles in a graphic form with optional color and auditory capabilities on a monitor. The patient was asked to watch the monitor and follow the display for contraction and relaxation of her pelvic floor muscles. The aim was to be able to hold the contraction for 10 seconds but if patient was not able to do so, she was then asked to begin with shorter duration and gradually increase to 10 seconds. In between contraction there is a phase of relaxation which lasts for 10 seconds. In one session a set of 10 contractions were done. She was asked to perform sessions of 10 contractions 3 times a day at home till her next visit.

Both the groups were given pelvic floor muscle therapy programme over 12 weeks. They had 9 supervised therapy sessions in hospital-once weekly for first 6weeks (6 sessions) and once fortnightly for next 6 weeks (3 sessions). They were instructed to perform the exercises three times a day at home

Follow up was done by observing change in maximum vaginal squeeze pressure and QOL, at 4,8 and 12 weeks (patients were followed at 4 and 8 weeks just to check their adherence to training so the results at the end of 4 and 8 weeks were not included in results). All observations were recorded on a predesigned case proforma using the King's health questionnaires and OAB symptoms questionnaires. ${ }^{18,19}$ OABSS-Comprises of four parameters with maximum score of 15 (frequency [0-2], nocturia [0-3], urgency [0-5], urge incontinence [05]).

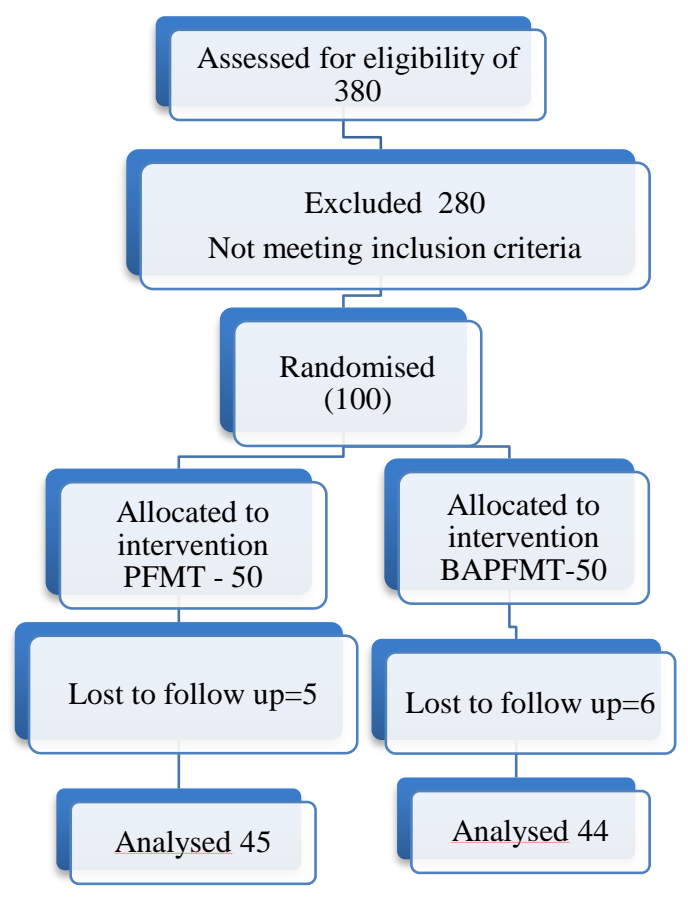

Figure 1: Flow of participants in the study.

Primary outcomes measured were overactive bladder symptom score, quality of life score, pelvic floor muscle strength before and maximum vaginal squeeze pressure, all before and after treatment (these scores were calculated by using OABSS questionnaire, King's health questionnaire and maximum vaginal squeeze pressure is documented in the biofeedback machine). Secondary outcomes studied were sociodemographic profile and adverse effects of treatments between the two groups. 


\section{Statistical analysis}

Data was entered on SPSS 21 software, and analysed at the end of the study applying appropriate statistical tests like student t-test for continuous data and chi -square test for quantitative data were applied. Pearson's chi square, Likelihood ratio, Fisher's exact test and Mean Whitney's test were used to compare various variables. For statistical analysis, SPSS17.0 software was used. For all statistical analysis, level of significance was taken as $\mathrm{p}<0.05$.

\section{RESULTS}

Out of the hundred women, 11 were lost to follow up -5 in Group A (PFMT) and 6 in Group B (BAPFMT group); thus leaving only 89 women for final analysis $(n=45$ in PFMT and $n=44$ in BAPFMT) at end of 12 weeks (Figure 1). The two groups were found comparable with respect to age, BMI, menstrual status and parity (Table 1). (p value-age (0.137), BMI (0.127), parity (0.904) as shown in Table 1.

In both Groups A and B there was statistical significant improvement in overactive symptom score, quality of life, maximal vaginal squeeze pressure at the end of 12 weeks in both groups individually, as depicted in Table 2 and 3.

Table 1: Sociodemographic profile and maternal characteristics in two groups.

\begin{tabular}{|c|c|c|c|c|}
\hline Characteristics & \multicolumn{2}{|c|}{ Group A } & \multicolumn{2}{|c|}{ Group B } \\
\hline \multicolumn{5}{|l|}{ Age (years) } \\
\hline$<40$ & 13 & 26 & 9 & 18 \\
\hline $40-50$ & 20 & 40 & 15 & 30 \\
\hline $50-60$ & 8 & 16 & 17 & 34 \\
\hline$>60$ & 9 & 18 & 9 & 18 \\
\hline \multicolumn{5}{|l|}{ BMI ( kg/m²) } \\
\hline$<18.5$ & 0 & 0 & 0 & 0 \\
\hline $18.5-24.9$ & 23 & 46 & 12 & 24 \\
\hline$\geq 25$ & 27 & 54 & 38 & 76 \\
\hline \multicolumn{5}{|c|}{ Menopausal status } \\
\hline Premenopausal & 43 & 86 & 43 & 86 \\
\hline Menopausal & 7 & 14 & 7 & 14 \\
\hline \multicolumn{5}{|l|}{ Parity } \\
\hline$<=2$ & 18 & 36 & 20 & 40 \\
\hline $3-4$ & 22 & 44 & 20 & 40 \\
\hline$>4$ & 10 & 20 & 10 & 20 \\
\hline
\end{tabular}

Table 2: Change in variables from baseline to 12 weeks in group A (PFMT).

\begin{tabular}{|c|c|c|c|c|c|}
\hline Variable & Mean & SD & Standard error & T value & P value \\
\hline \multicolumn{6}{|c|}{ Overactive bladder symptom score \# } \\
\hline Baseline & 8.72 & 3.03 & 0.43 & \multirow{2}{*}{6.87} & \multirow{2}{*}{$<0.001$} \\
\hline 12 weeks & 7.18 & 4.11 & 0.61 & & \\
\hline \multicolumn{6}{|c|}{ QOL I (General health perception, incontinence impact)\$ } \\
\hline Baseline & 111.79 & 41.59 & 5.88 & \multirow{2}{*}{7.298} & \multirow{2}{*}{$<0.001$} \\
\hline 12 weeks & 79.78 & 50.72 & 7.56 & & \\
\hline \multicolumn{6}{|c|}{ QOL II (role, social, physical limitation, personal relationship, sleep, emotions, severity measures)* } \\
\hline Baseline & 357.47 & 114.05 & 16.13 & \multirow{2}{*}{12.72} & \multirow{2}{*}{$<0.001$} \\
\hline 12 weeks & 242.60 & 148.03 & 22.07 & & \\
\hline \multicolumn{6}{|c|}{ Maximum vaginal squeeze pressure $(\mathbf{m m ~ H g})^{* *}$} \\
\hline Baseline & 12.58 & 7.18 & 1.02 & \multirow{2}{*}{-6.20} & \multirow{2}{*}{$<0.001$} \\
\hline 12 weeks & 14.94 & 8.14 & 1.21 & & \\
\hline
\end{tabular}

\#OABSS-Comprises of four parameters with maximum score of 15 (frequency [0-2], nocturia [0-3], urgency [0-5], urge incontinence [0-5]; \$ QOL I consists of two parameters-general health perception (GHP) and incontinence impact. Score is calculated from the formulae given in King's health questionnaire. Score of GHP is 1-5 and incontinence impact is 1-4. [Formulae: (score to GHP-1/4) x100, (score of incontinence impact-1/3) x100]; *QOL II consists of seven parameters-role limitation, social limitation, physical limitation, personal relationship, sleep, emotions and severity measures. Score for all parameters is between ( 0 3 ). [Formulae:(score to role limitation-2/6)x100,(score to physical limitation-2/6)x100, (formulae of role limitation if score is equal to or more than 1 then:(score to role limitation -3/9)x100 and if score is zero then: (score to role limitation-2/6)x100, formulae for personal relationship if score is equal to or more than 2:(score to personal relationship-2/6)x100, if score is equal to 1 :(score to personal relationship-1/3)x100, if score is zero then treat as missing value,(score to emotions-3/9)x100,(score to sleep2/6)x100,(score to severity measures-4/12)x100]; **Maximum vaginal squeeze pressure documented from the biofeedback machine.

There was $18.78 \%$ and $44.64 \%$ improvement in vaginal squeeze pressure in PFMT and BAPFMT respectively at the end of 12 weeks. However the improvement was not statistically significant ( $\mathrm{p}$ value-0.487). There was
$17.66 \%$ and $13.6 \%$ improvement in Overactive bladder symptom score in PFMT and BAPFMT respectively at the end of 12 weeks. There was a statistically significant improvement in QOL score Part I (28.63\% and 27.03\% 
improvement in PFMT and BAPFMT) and II (32.1\% and $26.7 \%$ improvement) at 12 weeks in both groups (Table 4 to 6$)$.
Between the two groups, Group B had significantly better results when comparing maximum vaginal squeeze pressure but QOL I, II and OABSS had no statistically significant improvement (Table 5 to 7 ).

Table 3: Change in variables from baseline to 12 weeks in group B (BAPFMT).

\begin{tabular}{|c|c|c|c|c|c|}
\hline Variable & Mean & SD & Standard error & T value & p value \\
\hline \multicolumn{6}{|c|}{ Overactive bladder symptom score\# } \\
\hline Baseline & 9.84 & 2.83 & 0.40 & \multirow{2}{*}{7.372} & \multirow{2}{*}{$<0.001$} \\
\hline 12 weeks & 8.0 & 3.70 & 0.56 & & \\
\hline \multicolumn{6}{|c|}{ QOL I (General health perception, incontinence impact)\$ } \\
\hline Baseline & 121.95 & 35.90 & 5.08 & \multirow{2}{*}{5.36} & \multirow{2}{*}{$<0.001$} \\
\hline 12 weeks & 88.98 & 58.88 & 8.42 & & \\
\hline \multicolumn{6}{|c|}{ QOL II (role, social, physical limitation, personal relationship, sleep, emotions, severity measures)* } \\
\hline Baseline & 357.76 & 116.22 & 16.44 & \multirow{2}{*}{9.28} & \multirow{2}{*}{$<0.001$} \\
\hline 12 weeks & 262.13 & 150.41 & 22.68 & & \\
\hline \multicolumn{6}{|c|}{ Maximum vaginal squeeze pressure (mm Hg)** } \\
\hline Baseline & 9.52 & 6.24 & 0.88 & \multirow{2}{*}{-6.88} & \multirow{2}{*}{$<0.001$} \\
\hline 12 weeks & 13.77 & 7.77 & 1.17 & & \\
\hline
\end{tabular}

Table 4: Change in modified oxfords scale over 12 weeks in both groups.

\begin{tabular}{|lllll|}
\hline GROUP A & Id $^{\mathrm{d}}$ & II $^{\mathrm{e}}$ & III $^{\mathrm{f}}$ & Total $^{\text {\% improvement }}$ \\
\hline No Improvement $^{\mathrm{b}}$ & $9(20)$ & $12(26.6)$ & $6(13.3)$ & 60 \\
\hline Improvement $^{\mathrm{c}}$ & $6(13.3)$ & $4(8)$ & $8(17.7)$ & 40 \\
\hline GROUP B & & & & \\
\hline No Improvement & $7(15.9)$ & $5(11.3)$ & $1(2.2)$ & 29.55 \\
\hline Improvement & $14(31.3)$ & $15(34.09)$ & $2(4.5)$ & 70.4 \\
\hline
\end{tabular}

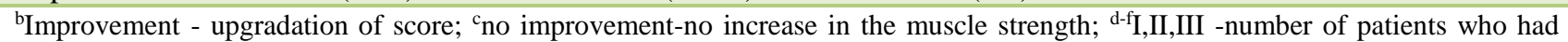
improvement and no improvement in their modified oxford score from their baseline score 1,2,3 respectively.

Table 5: Mean \pm SD (standard deviation) (\%) improvement in all variables at 12 weeks in both groups.

\begin{tabular}{|llll|}
\hline Outcome Mean \pm SD $(\%)$ improvement at 12 weeks & Group A & Group B & P value \\
\hline $\begin{array}{l}\text { OABSS (score at baseline and } 12 \text { weeks and } \\
\text { percentage improvement) }\end{array}$ & 8.72 to $7.18(17.66)$ & 9.84 to $8(13.6)$ & $<0.001$ \\
\hline $\begin{array}{l}\text { QOL I (score at baseline and } 12 \text { weeks and } \\
\text { percentage improvement) }\end{array}$ & 111.79 to $79.78(28.63)$ & 121.95 to $88.98(27.03)$ & $<0.001$ \\
\hline $\begin{array}{l}\text { QOL II (score at baseline and } 12 \text { weeks and } \\
\text { percentage improvement) }\end{array}$ & 357.47 to $242.60(32.1)$ & 357.76 to $262.13(26.7)$ & $<0.001$ \\
\hline $\begin{array}{l}\text { Maximum vaginal squeeze pressure (score at } \\
\text { baseline and 12 weeks and percentage improvement) }\end{array}$ & 12.58 to $14.94(18.78)$ & 9.52 to $13.77(44.64)$ & $<0.001$ \\
\hline
\end{tabular}

Table 6: Comparison of various variables in between two groups over 12 weeks of follow up.

\begin{tabular}{|c|c|c|c|c|c|}
\hline & Group & $\mathbf{N}$ & Mean & t-value & p-value \\
\hline \multirow{2}{*}{ OABSS baseline } & Group A & 50 & 8.72 & 1.91 & 0.059 \\
\hline & Group B & 50 & 9.84 & & \\
\hline \multirow{2}{*}{ OABSS 12 weeks } & Group A & 45 & 7.18 & 0.992 & 0.324 \\
\hline & Group B & 44 & 8.00 & & \\
\hline \multirow{2}{*}{ *GHP baseline } & Group A & 50 & 54.50 & 1.307 & 0.194 \\
\hline & Group B & 50 & 60.00 & & \\
\hline \multirow{2}{*}{ *GHP 12 weeks } & Group A & 45 & 40.56 & 1.033 & 0.305 \\
\hline & Group B & 44 & 46.59 & & \\
\hline Incontinence baseline & Group A & 50 & 57.29 & 1.12 & 0.265 \\
\hline
\end{tabular}




\begin{tabular}{|c|c|c|c|c|c|}
\hline & Group & $\mathbf{N}$ & Mean & t-value & p-value \\
\hline & Group B & 50 & 61.95 & & \\
\hline \multirow{2}{*}{ Incontinence 12 weeks } & Group A & 45 & 39.22 & 0.553 & 0.582 \\
\hline & Group B & 44 & 42.39 & & \\
\hline \multirow{2}{*}{$* *$ Role baseline } & Group A & 50 & 59.30 & 0.194 & 0.846 \\
\hline & Group B & 50 & 58.63 & & \\
\hline \multirow{2}{*}{ **Role 12 weeks } & Group A & 45 & 36.63 & 0.78 & 0.437 \\
\hline & Group B & 44 & 40.87 & & \\
\hline \multirow{2}{*}{$\begin{array}{l}\text { Physical limitation } \\
\text { baseline }\end{array}$} & Group A & 50 & 57.30 & 1.296 & 0.198 \\
\hline & Group B & 50 & 61.96 & & \\
\hline \multirow{2}{*}{$\begin{array}{l}\text { Physical limitation } 12 \\
\text { weeks }\end{array}$} & Group A & 45 & 41.07 & 1.8 & 0.075 \\
\hline & Group B & 44 & 49.59 & & \\
\hline \multirow{2}{*}{$\begin{array}{l}\text { Social limitation } \\
\text { baseline }\end{array}$} & Group A & 50 & 60.50 & 0.206 & 0.837 \\
\hline & Group B & 50 & 59.72 & & \\
\hline \multirow{2}{*}{$\begin{array}{l}\text { Social limitation } 12 \\
\text { weeks }\end{array}$} & Group A & 45 & 44.89 & 0.052 & 0.959 \\
\hline & Group B & 44 & 45.16 & & \\
\hline \multirow{2}{*}{ \#Pr baseline } & Group A & 50 & 28.84 & 1.333 & 0.186 \\
\hline & Group B & 50 & 23.63 & & \\
\hline \multirow{2}{*}{ \#Pr 12 weeks } & Group A & 45 & 14.80 & 1.057 & 0.293 \\
\hline & Group B & 44 & 10.59 & & \\
\hline \multirow{2}{*}{ Emotions baseline } & Group A & 50 & 47.95 & 0.872 & 0.386 \\
\hline & Group B & 50 & 51.06 & & \\
\hline \multirow[t]{2}{*}{ Emotions 12 weeks } & Group A & 45 & 34.04 & 0.924 & 0.358 \\
\hline & Group B & 44 & 38.35 & & \\
\hline \multirow{2}{*}{ Sleep baseline } & Group A & 50 & 45.96 & 0.05 & 0.96 \\
\hline & Group B & 50 & 46.13 & & \\
\hline \multirow{2}{*}{ Sleep 12 weeks } & Group A & 45 & 29.71 & 0.45 & 0.654 \\
\hline & Group B & 44 & 31.59 & & \\
\hline \multirow{2}{*}{$\begin{array}{l}\text { Severity measures } \\
\text { baseline }\end{array}$} & Group A & 50 & 57.62 & 0.199 & 0.842 \\
\hline & Group B & 50 & 56.64 & & \\
\hline \multirow{2}{*}{$\begin{array}{l}\text { Severity measures } 12 \\
\text { weeks }\end{array}$} & Group A & 45 & 41.46 & 0.763 & 0.447 \\
\hline & Group B & 44 & 45.98 & & \\
\hline
\end{tabular}

*GHP-General health perception; **ROLE-Role limitation; \#PR-Personal relationship

Table 7: Percentage cure and improvement in both groups at the end of 12 weeks.

\begin{tabular}{|c|c|c|c|}
\hline & Complete cure & Improvement & \\
\hline PFMT & $42.1 \%$ & $57.9 \%$ & \multirow{2}{*}{$\mathrm{p}$ value $=0.501$} \\
\hline BAPFMT & $31.5 \%$ & $68.5 \%$ & \\
\hline
\end{tabular}

\section{DISCUSSION}

Overactive bladder $(\mathrm{OAB})$ is a frequently encountered clinical entity in gynaecological practice. The first line of treatment is behavioral therapy including PFMT, which improves pelvic floor muscle strength, and thus the symptoms of OAB. The two groups were found comparable with respect to age, BMI, menstrual status and parity ( $\mathrm{p}$ value-age (0.137), BMI (0.127), parity $(0.904)$. This reflected more so the population of women seeking professional help in the teaching hospital.

There was statistically significant improvement in OABSS, QOL, muscle strength and squeeze pressure in both groups at the end of 12 weeks but the improvement if compared in both groups was not statistically significant.

There was statistically significant improvement in OABSS in both groups at the end of 12 weeks, similar to the study by Tu-Zhen-Xu et al. Also the outcome was akin to the study reported by $\mathrm{Ng} \mathrm{SC}$ et al, who indicated that a home-based pelvic floor muscle exercise could improve symptoms significantly in the study group at 6 months. ${ }^{20}$

The results of vaginal squeeze pressure in biofeedback group were in consonance with those concluded by Ibrahim Khalil Ibrahim et al, who in their research found a significantly higher improvement in maximal vaginal squeeze pressure in the biofeedback group versus the 
conventional group (22.3\% versus $6.1 \%$, respectively). ${ }^{21}$ However, Brugio KL et al, found no difference in quality of life after biofeedback assisted PFMT or verbal feedback PFMT. ${ }^{14}$

In the present study also the higher improvement in pelvic muscle strength by BAPFMT did not translate into higher improvement in QOL. (Due to short period of study and small sample size).

Limitation of the study was, the sample size of present study limited the comprehensive conclusions that can be drawn. Further studies are needed to choose the optimal training tool for PFMT.

\section{CONCLUSION}

Pelvic floor muscle training alone or in combination with biofeedback assistance is promising to alleviate $\mathrm{OAB}$ symptoms effectively and improve the overall quality of life of the patients with overactive bladder (there is improvement in QOL and OABSS in both groups but which is better could not be concluded due to limitation of study). Addition of biofeedback to PFMT may be a useful adjunct but more studies with larger sample size and longer duration are required.

\section{ACKNOWLEDGMENTS}

Authors would like to thank all patients who willingly consented to be a part of the study.

Funding: No funding sources

Conflict of interest: None declared

Ethical approval: The study was approved by the Institutional Ethics Committee

\section{REFERENCES}

1. Abrams P, Kelleher CJ, Kerr LA, Rogers RG. Overactive bladder significantly affects quality of life. Am J Managed Care. 2000;6(suppl):S580-90.

2. Wein AJ, Rovner ES. Definition and epidemiology of overactive bladder. Urolo. 2002;60(5 Suppl 1):712.

3. Brown JS, Subak LL, Gras J. Urge incontinence: the patient's perspective. J Women's Health. 1998;7:1263-9.

4. Samuelsson E, Victor A, Tibblin G. A population study of urinary incontinence and nocturia among women aged 20-59 years. Acta Obstet Gynecol Scand. 1997;76:74-80.

5. Gentili A, Weiner DK, Kuchi M, Edinger JD. Factors that disturb sleep in nursing home residents. Aging ClinExp Res. 1997;9:207-13.

6. Brown JS, McGhan WF, Chokroverty S. Comorbidities associated with overactive bladder. Am J Managed Care. 2000;6(suppl):S574-79.

7. Johansson C, Hellstrom L, Ekelund P, Milsom I. Association between urinary incontinence and urinary tract infections and fractures in postmenopausal women. Maturitas. 1996;23:265-71.

8. Brown JS, Vittinghoff E, Wyman J. Urinary incontinence: does it increase risk for fall and fracture? J Am Geriatr Soc. 2000;48:721-5.

9. Wagner $\mathrm{TH}, \mathrm{Hu} \mathrm{TW}$. Economic costs of urinary incontinence in 1995. Urol. 1998;51:355-61.

10. Wilson PD, Herbison RM, Herbison JP. Obstetric practice, and the prevalence of urinary incontinence three months after delivery. BJOG. 1996;103:154-61.

11. Ellsworth PI, MD Professor of Urology, University of Massachusetts Medical School; Chief, Division of Pediatric Urology, Department of Urology, UMass Memorial Medical Center.

12. Dumoulin C, Hay-Smith J, Habée-Séguin GM, Mercier J. Pelvic floor muscle training versus no treatment,for urinary incontinence in women:a short version Cochrane systematic review with metaanalysis. Neurourol Urodyn. 2015;34(4):300-8.

13. Hay-Smith EJ, Dumoulin C. Pelvic floor muscle training versus no treatment, or inactive control treatments, for urinary incontinence in women. Cochrane Database Syst Rev. 2006;1:CD005654.

14. Burgio KL, Whitehead WE, Engel BT. Urinary incontinence in the elderly. Bladder-sphincter biofeedback and toileting skills training. Ann Intern Med. 1985;103(4):507-15.

15. Wang AC, Wang YY, Chen MC. Single-blind, randomized trial of pelvic floor muscle training, biofeedback muscle training, and electrical stimulation in the management of overactive bladder. Urol. 2004;63:61-6.

16. Liaw MY, Kuo $\mathrm{CH}$. Biofeedback pelvic floor muscle training for voiding dysfunction and overactive bladder. Incont Pelvic Floor Dysfunction. 2007;1:135.

17. Ferreira CHJ, Barbosa PB, de Oliveira Souza. Interrater reliability study of the modified Oxford Grading Scale and the Peritron manometer. Physiotherapy. 2011;97:132-8.

18. Kelleher CJ, Cardozo LD, Khullar V, Salvatore S. A new questionnaire to assess the quality of life of urinary incontinent women. Br J Obstet Gynaecol. 1997;104:1374-9.

19. Ref-Lin Ting-Yi, Chou Lung-ChiehEric. Assessment of Overactive Bladder (OAB) Symptom Scores. Incont Pelvic Floor Dysfunction. 2009;3(Suppl):914.

20. Ng SC, Lin TL, Chang SJ, Tai HL, Hu SW, Chen GD. Nursing intervention to enhance efficacy of home practice of pelvic floor muscle exercises in treating mixed urinary incontinence. Int Urogynecol J Pelvic Floor Dysfunct. 2008;19(5):637-42.

21. Ibrahim IK, Hameed MMA, Taher EM, Shaheen EM, GawdatElsawya MA. Efficacy of biofeedbackassisted pelvic floor muscle training in females with pelvic floor dysfunction. Alexandria J Med. 2015;51(12):137-42.

22. Mantle J. Physiotherapy for incontinence. Cardoza L, Staskin D, editors. Text- book of female urology and 
urogynaecology. London: Isis Medical Media Ltd;2001:351-358.

23. Haslem J. Therapeutic management of incontinence and pelvic pain. 2nd ed. London: Springer; 2007.

24. Kegel AH. Progressive resistance exercise in the functional restoration of the perineal muscles. Am J Obstet Gynaecol. 1948;56:238-49.

25. Miller JM, Perucchini D, Cardichi LT, Delancey JOL, Ashton-Miller J. Pelvic floor muscle contraction during a cough and decreased vesical neck mobility. Obstet Gynecol. 2001;97:255-60.
26. Miller JM, Ashton-Miller JA, DeLancey JOL. A pelvic muscle pre contraction can reduce coughrelated urine loss in selected women with mild SUI. J Am Geriatr Soc. 1998;46:870-4.

Cite this article as: Badda $\mathrm{P}$, Batra A, Marwah S, Dewan R. Pelvic floor muscle training with and without biofeedback in treatment of overactive bladder. Int J Reprod Contracept Obstet Gynecol 2019;8:2997-3004. 